\title{
AN APPROACH FOR INCREASING FLEXIBILITY IN GREEN SUPPLY CHAINS DRIVEN BY SIMULATION
}

\author{
Markus Rabe \\ Adrienn Horvath \\ Technical University Dortmund \\ Leonard-Euler-Straße 5 \\ D- 44227 Dortmund, GERMANY
}

\author{
Sven Spieckermann \\ Till Fechteler \\ SimPlan AG \\ Edmund-Seng-Str. 3-5 \\ D- 63477 Maintal, GERMANY
}

\begin{abstract}
Flexibility is a relevant topic in the field of green supply chains (GSC), as disturbances lead to additional transport and storage, frequently aggravated by energy-consuming air conditioning requirements. This paper discusses how simulation can support to establish flexible GSCs with specific focus on decreasing $\mathrm{CO}_{2}$ and energy consumption. For this purpose, the term flexibility is structured into categories, and methodological approaches driven by simulation in supply chains are studied. Flexibility requirements in the context of a GSC are analyzed and potential support derived for increasing this flexibility, gained by a join of simulation techniques, data models and morphological characteristics of flexibility. An approach for systematic flexibility analysis is presented on the grounds of a data mart that represents both internal and external factors influencing GSC scenarios.
\end{abstract}

\section{INTRODUCTION}

The continuous growth of $\mathrm{CO}_{2}$ emissions and energy consumption is a major cause for greenhouse gas emissions and in consequence for climate change, which has the largest negative impact on our environment (Diabat and Simchi-Levi 2009). There are a lot of manufacturing organizations who deal with measuring and reducing the size of their carbon footprint and the amount of energy (Van Slooten 2009), but there are fewer supply chains (SC) which can support these intentions, because there exists no adequate method or general set-up for these activities (Rabe and Deininger 2011). Even though it is generally agreed that being environmentally responsible can induce a competitive advantage, SCs will inevitably need to respect this aspect in the future.

Several methods can be applied to analyse steady-state SCs, but this is not sufficient. SCs are in the center of demand, production, and environmental as well as social constraints. Therefore, most SCs are highly dynamic systems, influenced by continuous technological changes, innovations, traffic operation and policy, many kinds of costs (e.g., energy, duties, taxes, wages, etc.) and the uncertainties of an always changing economy. Hence, SCs have to provide a high grade of flexibility to cope with these requirements. In the light of these challenges the goal of this paper is to understand how discrete event simulation can support increasing flexibility in SCs with the specific focus on decreasing $\mathrm{CO}_{2}$ emissions and energy consumption and keeping them low even under disturbances. For the steady-state case, we can find approaches for the description of green supply chains and even standards like GreenSCOR (Chenga 2011). Surprisingly, there seem to be few researches in the exploitation of discrete event simulation techniques for the flexibility evaluation of green supply chains under disturbance, and the authors have not been able to find a previous paper with this focus. To meet our goal, we first introduce the relevant terms of the research topic with specific scope on environment-friendliness in the SC and the concept of flexi- 
bility. The main section portrays a brief explanation of how we bring together simulation and flexibility on different levels in a model and some intricacies involved in simulation.

\section{GREEN SUPPLY CHAINS AND FLEXIBILITY}

In this chapter we introduce the most important terms that will be used in conjunction with simulation, namely green supply chains and flexibility. As a first step, we define what "green supply chain" means, which kind of environment-friendly actions exist and how the method Life Cycle Assessment (LCA) helps to identify the nodes of a green supply chain that have to be improved by taking flexibility into consideration. In the next paragraph we state essential definitions and the historical background of manufacturing flexibility. Then, we discuss further morphological characteristics of flexibility that should be analyzed within detail in the next chapter, based on a modeling approach and an example.

\subsection{How Can a Supply Chain be "Green"?}

The complexity of SCs has risen significantly because of the new and increasing requirements and possibilities - like sustainability, globalization and environmental friendliness (Rabe and Deininger 2011). In this context the term "green supply chain" became also a new important topic of research, which does not have a standardized definition yet. For instance, Godfrey (1998) defines GSCs as practices of monitoring and improving environmental performance in the SC. Green et al. (1996) state that green supply refers to the way in which innovations in SC management and industrial purchasing are considered in the context of the environment. Hervani et al. (2005) interpreted GSC as aggregation of SC activities in relation to the support of the protection of the environment. Examples for these activities include Green Design, Selection of Green Material, Selection of Green Suppliers, Green Production, Green Logistics, Green Packaging, Gaining Green Certification, and Reverse Logistics (Rabe and Deininger 2011). Rao and Holt (2005) point out that the issue of green focuses on the minimization or elimination of solid, energy, emissions, chemicals or hazardous waste by material suppliers, contractors, service contractors, vendors, distributors, and end users within the SC. From this multitude of environment-friendly action fields, in this paper we focus on climate protection and on such activities which reduce carbon emissions and so decrease energy use within the SC. More precisely, we examine the sector logistics because its emissions continued to grow spectacularly in the last decades (in contrast to other determining sectors in this topic, like manufacturing and construction) (Clausen and Hesse 2008). More specifically, this paper discusses the section of the SC from the finished product transported from the manufacturing plant up to the retail store.

As a method for collecting, selecting and analyzing the data which influence a SC's green strategy, we have chosen Life Cycle Assessment (LCA). LCA is a very effective technique for these requirements, because this concept uses the most accurate and relevant data for identifying information that can show how environment-friendly the SC is at a specific point of time. Also, LCA is able to help us to define what the further options of the GSC improvement are. Moreover, it supports the "Compilation and evaluation of the inputs, outputs and the potential environmental impacts of a product system throughout its life cycle" (ISO 14000, 2007), relying on international trusted databases like ecoinvent or European Reference Life Cycle Database (Lindskog and Berglund 2011). However, we have to understand that LCA principally covers the whole product life cycle, while we restrict our study to a clearly limited phase of product distribution. Therefore, we have to respect this constraint in our approach.

\subsection{Flexibility}

Flexibility is one of the most important requirements of modern SCs, because it facilitates the response to challenges like globalization, technological changes, innovations and the continuous economical uncertainty with little penalty in time, effort, cost or performance (Zhang et al. 2002a; 2002b; 2006). With flexibility, SCs can achieve a huge competitive advantage and ensure their survival in this ever changing world. In addition, this ability is also needed to meet the demand of environment-friendly customers, whose number is continually increasing (Straube and Doch 2011). 
The concept of flexibility has been first introduced in the work of Lavington (1921), who points out a connection between variability and the value of flexibility taking the "risk arising from the immobility of invested resources into consideration". After that, three functional perspectives of flexibility have been evolved. The first is the economic one that is based on the research of Stigler (1939), who defines flexibility as the ability of a single-product firm to make output decisions at relatively low costs, when exogenous shocks are impacting on the organization. In the 1980ies and 1990ies, the manufacturing perspective is emphasized, while conceptual frameworks, models and measures for manufacturing flexibility are developed (Bertrand 2003; Wadhwa and Rao 2003). In the last 10-15 years organizations and SCs are also getting into the focus of academic studies (Koste and Malhotra 1999). From this perspective, flexibility is the firm's ability to suffer limited change without serious disorganization (Sethi and Sethi 1990; Zhang et al. 2002b; Zhang et al. 2009). The tools of such kind of non-technological flexibility are for instance decentralization, divisionalization and project management, job enrichment or enlargement concepts, management of SC capabilities or business strategies (Awwad and Almahamid 2008; Child 1972).

Referring to the literature, four dimensions of flexibility are classified (Day 1994; Zhang et al. 2002b): product development flexibility, manufacturing flexibility, logistics flexibility, and spanning flexibility. Product development flexibility means the ability to rapidly and effectively introduce new products and upgrade existing products by replying to customers' demands for design altering (Sethi and Sethi 1990). Manufacturing flexibility evolves when manufacturing resources and unsteadinesses are adequately managed and in parallel, different customer demands are taken into consideration (Zhang et al. 2003). In the focus of logistics flexibility are the changing requirements for delivery, support and service, which the organization has to treat in an effective and rapid manner (Perry 1991; Davis 1993; Day 1994; Bowersox and Closs 1996; Zhang et al. 2002b; Zhang et al. 2005). At least, spanning flexibility is present in a firm's life when horizontal information connections within the SC are created and ensured (Day 1994). Certainly these dimensions are typical of SCs too, because of the interrelations that exist between companies and organizations.

The different time horizons are also relevant to mention, because they can influence the decision making strategy and so the flexibility of a SC. There are three horizons that we can distinguish. Operational flexibility (short-term) corresponds to built-in procedures that permit a large range of responses to operational variables (e.g., sequencing, scheduling). Tactical flexibility (medium-term) for factories refers to actions that are undertaken before the plant is built and the organizational setup is determined (Carlsson 1989; Upton 1994). This horizon shows technological and organizational routines corresponding to how to deal with quantitative and qualitative changes considering production and product mix over the course of a business cycle etc. (Araujo and Spring 2002). For SCs, this means that tactical flexibility covers decisions done before deciding the physical setup of the network. Finally, strategic flexibility (long-term) determines how the firm or SC is positioning itself with respect to future challenges and opportunities (Carlsson 1989; Upton 1994).

The hierarchical levels of flexibility are the following: shop floor level flexibility (product, volume, routing), called basic flexibility, plant or company level (delivery, transshipment, postponement) which means system flexibility and aggregate level (sourcing, response, access, launch) which concludes the customer-supplier relationships in a SC (Sánchez and Pérez Pérez 2005). A SC is flexible on an aggregate level, if it can react to changes and new challenges and achieve appropriate results as a whole, and not only single participants of the SC have this ability.

Suarez (1991) pointed out that there are internal and external factors which influence flexibility. Among the internal factors of a SC those are found that are - at least in principle - under control of the organization (e.g., investing in faster trucks for transportation). External factors in contrast are independent of the specific SC and the participants of the SC cannot influence them, but need to adapt their SC accordingly (e.g., environmental regulations, macro-economical changes, behavior of the competitors, etc.).

The categories of flexibility discussed above are summarized in Figure 1. In the next chapter we will introduce and analyze a method which can help to increase the flexibility of GSCs, considering the organizational perspective, the logistics dimension (in a physical and a logical manner) and the tactical aspect 
on an aggregate level of this ability, related to the internal and external influential factors, as marked orange on Fig. 1.

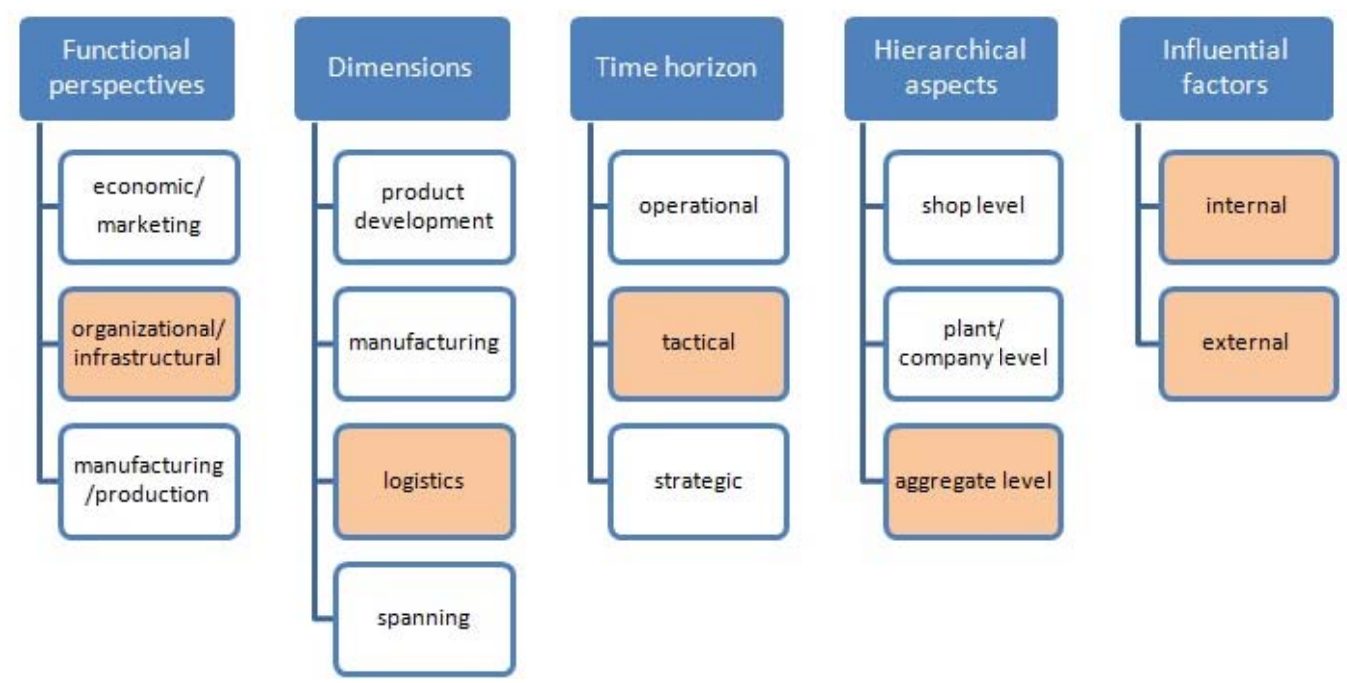

Figure 1: Categories of flexibility

\section{SIMULATION FOR SUPPLY CHAINS}

A survey of Terzi and Cavalieri (2004) shows that there are different ways to apply simulation in a supply chain context. One way is to use simulation for the design of the supply chain. Another way might be to support the supply chain operation. In supply chain design, simulation can e.g., support decisions on ramp up or shut down of locations (more generally called network design), on the capacity of production and warehouse sites, on the general assessment of transport options (e.g., different transporation modes such as transportation by ship, by train, or by truck), or on allocations of products to sites. In supply chain design and in daily supply chain operation simulation may help to adjust control parameters such as safety stock or lot sizes, to assess short-term options on transportation, and to forecast the "behavior" of the supply chain within the near future (i.e. within the next hours or days).

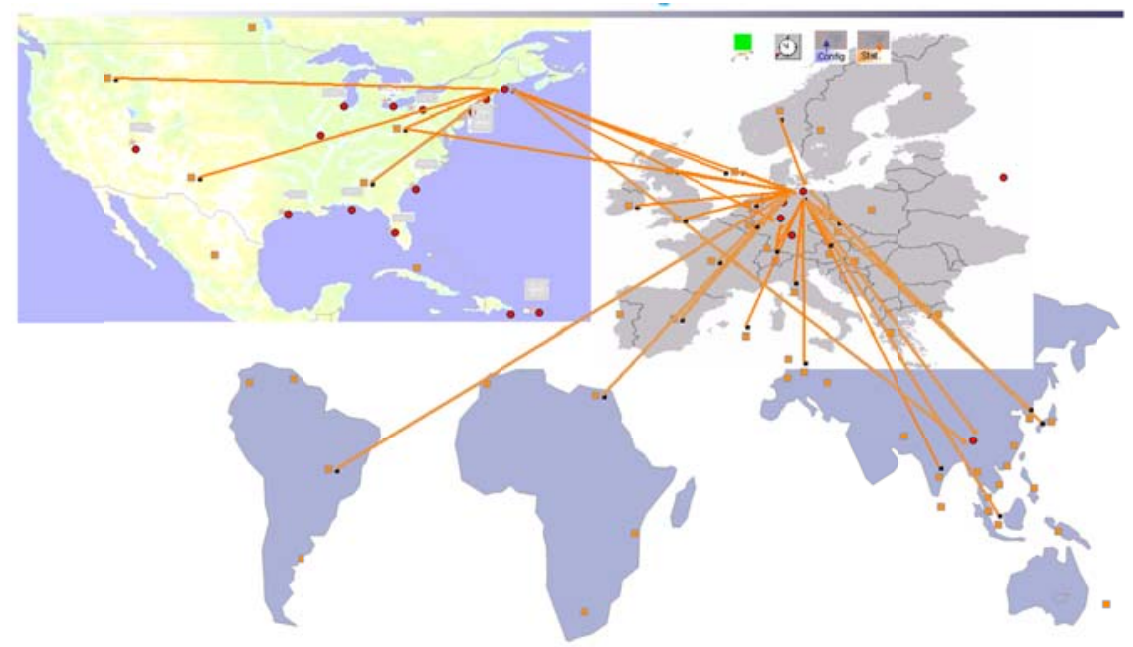

Figure 2: Sample from a supply chain simulation model 
Supply chain simulation projects quite often are part of a strategic initiative for a company or at least for a business unit of the company. Hence, also the objectives are rather strategic such as analysis of the existing supply chain structures, identification of bottlenecks and weaknesses within the supply chain structure, improved understanding of cost drivers for stock and transportation costs, and improved understanding of lead times and causes for stock out (Schulz and Spieckermann 2008).

In many cases of supply chain simulation it turns out to be painful and costly to generate a valid data model of all supply chain operations since not only information about the network is needed but also on orders, bills of material, rules on order and production control etc. (Chang and Makatsoris 2001). This challenge will even grow with the consideration of "green" aspects in supply chains.

In the context of this paper, it is necessary to point out that in the context of supply chains the term simulation does in many cases not refer to discrete-event simulation (DES) (Kleijnen 2005). However, with respect to the application of DES to supply chains it is rather common to use commercial simulation tools either stand-alone ones or to connect simulation to software with advanced planning features (APS software) or to ERP (Enterprise Resource Planning) systems (Banks et al. 2002). As an example, Figure 3 is a screenshot of a simulation model set up with the toolset ICON-SimChain, a combination of a commercial DES simulation tool (PlantSimulation), and the supply chain monitoring and operation software environment ICON (Alicke and Gutenschwager 2003). This toolset will be explained in the following sections as a background of the authors that could be enriched for the simulation of GSCs.

The toolset ICON-SimChain consists of three major parts: a graphical user interface used for model configuration, a data base in which all configuration data and simulation results are stored and a DES Supply Chain Simulation Framework based on Plant Simulation. In ICON-SimChain, all model elements are created automatically from a template library implemented in PlantSimulation. This library as a set of templates represents predefined ready-to-use building blocks for simulation experiments. A specific template combination is used to instantiate a specific simulation scenario with the aim to support SC decisions. Examples for templates within ICON-SimChain are "Depot (Site)" which is used to model enterprise locations (sites) and its transport relations to other sites or the template "Transport Route" which is used to model transports between locations. As described above, operational decision rules can be specified within the framework of the ICON environment.

The data model of ICON-SimChain is quite extensive. Therefore, this section gives an overview of the most important parts of the data model, only. To simulate supply chain data of considered locations, SKU (stock keeping units), the transport relations between locations (i.e. material flow) and information flow are necessary. The basic tables of the data model hold data which describe locations (production sites, hubs and customers), calendars, SKU and BOM (bill of material), carriers and means of transport, information delay, forecast errors, transport relations and sourcing (sequence of transport relations). Finally a scenario is defined by a set of configurations (see Figure 3).

\section{USING SIMULATION TO FACE FLEXIBILITY REQUIREMENTS}

In this paper, we discuss Discrete Event Simulation (DES) only, because it is an efficient method for analyzing time-variant systems where changes occur at discrete points in time. DES is also appropriate for analyzing powerful "what-if"-scenarios, which means it permits the comparison of various operational alternatives without changing the real system (Chang und Makatsoris 2001) and that is exactly what is needed when searching for more flexible green SCs, especially on the operational and tactical planning level (Hellström and Johnsson 2005).

The main aspect of the term flexibility is the ability of reacting to changes as pointed out in the previous sections. To support flexibility in SCs there is the need to take different "To Be" models into account where every "To Be" model represents an alternative scenario in respect to external influences on the SC, which facilitates supply-chain-planning too. To improve existing solutions like the one described in Section 3, a more generic and systematic modeling and data collection approach is required. The main outlines of this approach are specified in the following. 
Rabe, Spieckermann, Horvath, and Fechteler

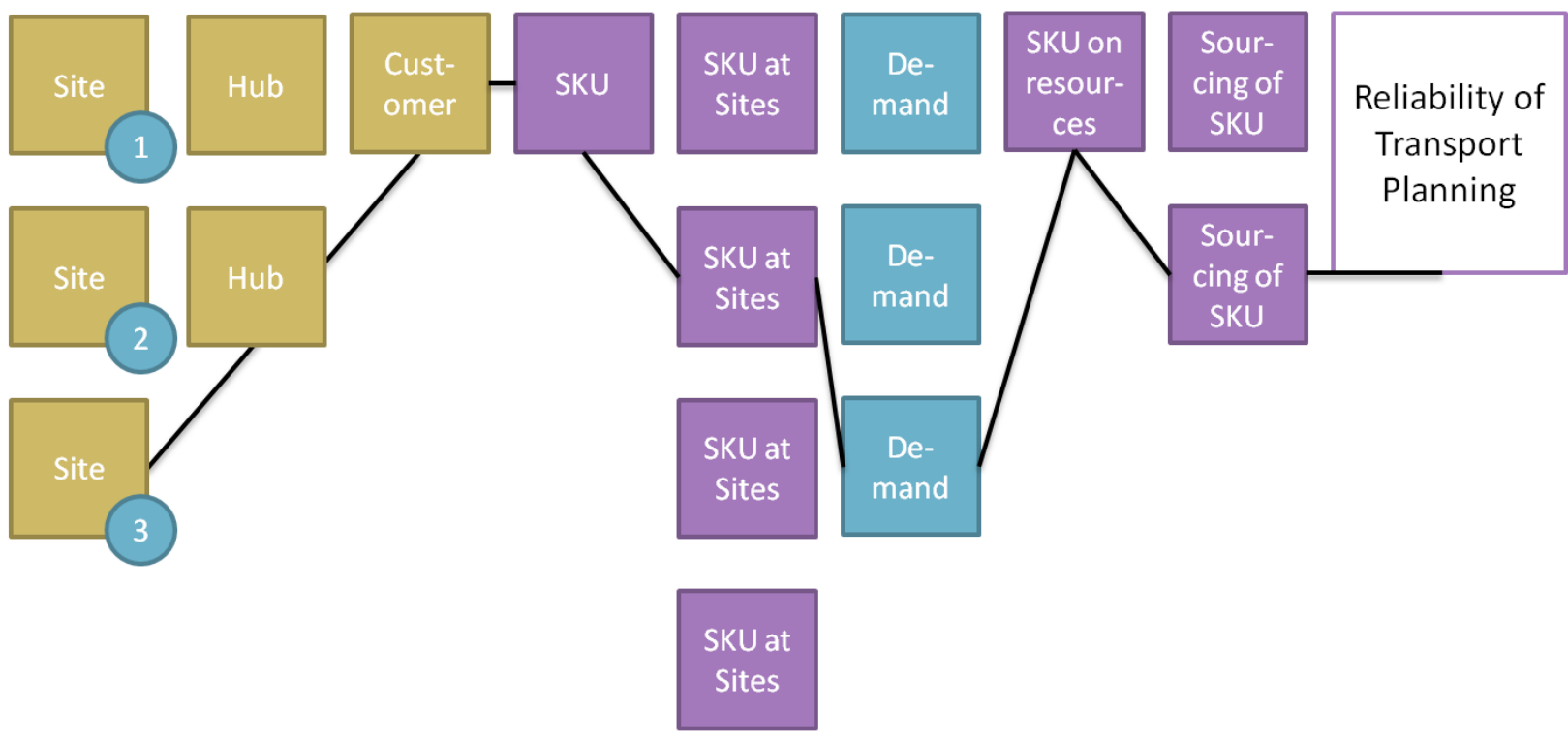

Figure 3: Scenario definition with the ICON-SimChain data model

\subsection{The General Modeling Approach}

The SC scope, defined by its entities and their general relationships, describes the categories and potential sources of data that can be used for the analysis (Fig. 4). These data, from the SC itself as well as from the environment that is influencing the SC, are brought together in a structured architecture, which we call "data mart". The data mart can be described as common view of enterprise data in which the physical storage is an underlaying data warehouse (Parimala and Pahwa 2006). The data mart contains multifarious data, represented by a diversity of data types related to different sources in various formats. The benefits of this architecture are data legibility, the support of company knowledge and the neglection of boundaries between data management and data movement (Liu 1999). For instance, there will be sensor data which are automatically collected by radio-frequency identification (RFID) systems or data imports from a legacy database. Additionally, the business logic workflows can be stored in respect to LCA. The data mart is divided into two conceptual parts. The first one represents the external factors that cannot be influenced by the participants of the SC. The second one includes the internal factors like the description of the current network. Both parts together are forming the data source for the simulation experiments. The main design element of the simulation approach is a template library which supports the experiment setup. The results of simulation experiments which form the flexibility evaluation will be mirrored back to the model.

\subsection{Data Mart}

The data mart is subdivided into the area of internal factors and the area of external factors. The internal factors are based on the SC itself. A distinction is made between two basic SC views. The first one, called the physical network, is made up of entities which describe the physical structure and its geographical transport relations. The major elements of the physical network are nodes (e.g., factory) and relations (e.g., transport path). The second view describes the rules also called policies which illustrate the business logic (Hicks 1999). The business logic defines how products move through the supply chain under the constraints set by the physical network as well as further constraints like the relationships among the products. As an example, let us assume a physical network with an intermediate storage between the manufacturing plant and the retail store. A related business logic could specify that under regular conditions all products go through the intermediate storage in order to optimize truck loads, but a product is 
transported directly from the plant to the retail store if the retailer's inventory is zero. The third component of the internal part are the company Key Performance Indicators (KPIs). The underlying principle is to enrich the statistical data by the reliable and actual data collected by monitoring systems of the company. The assumption here would be that it is more realistic and therefore precise to use e.g., the consumption of actually used vehicles than to take statistical average values, possibly being independent of the specific vehicle type, into account.

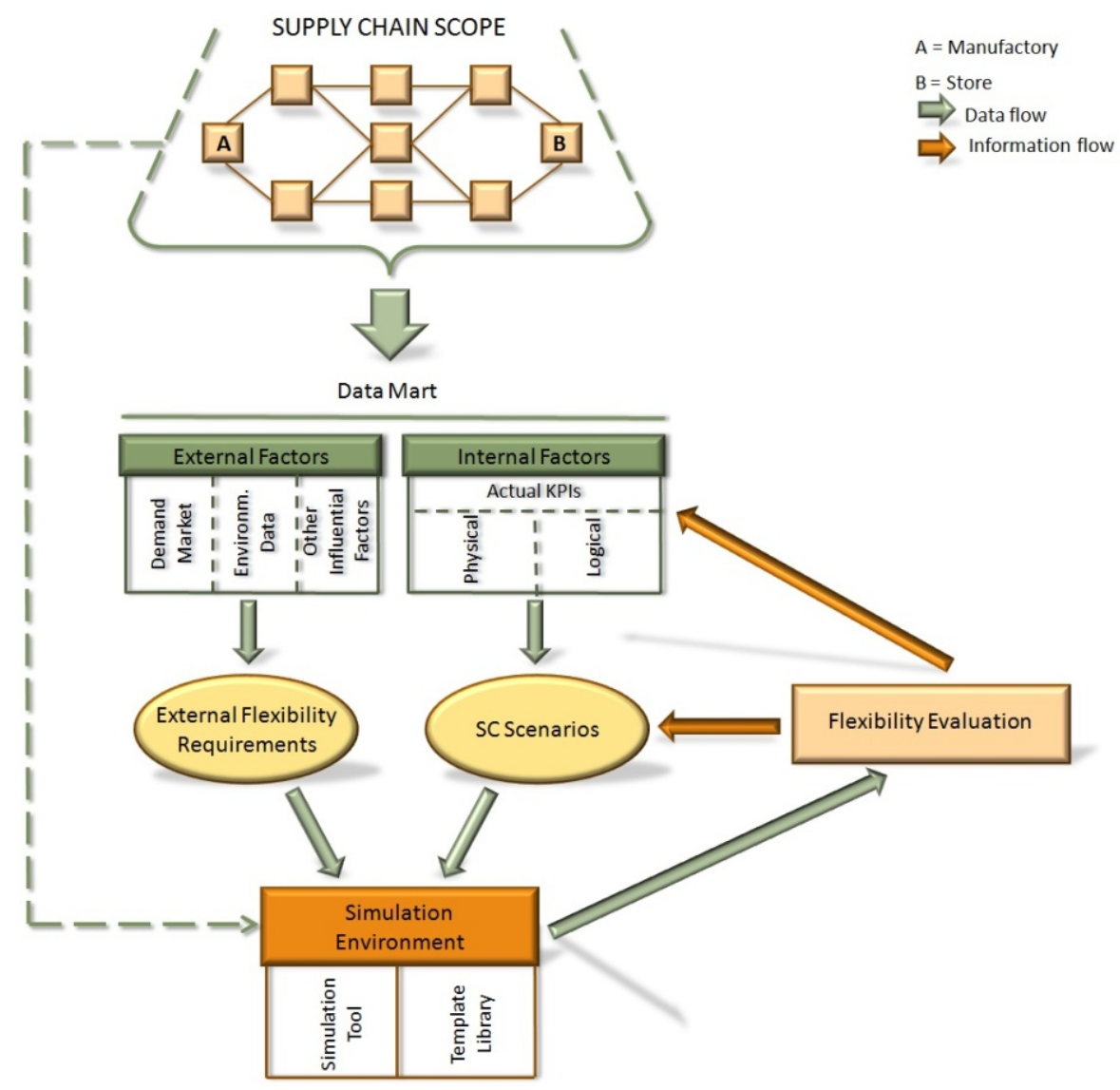

Figure 4: Flexibility model

The counterpart of internal data is the data base of external factors. These data is divided into different subclasses with respect to their function. In our approach we use three subclasses. The first one describing traditional external SC factors like customer demand. The second one related to the term "green" in the described SC, i.e. it refers to environmental data. These data are stored in enterprise or public databases and is containing information about global KPIs, like the $\mathrm{CO}_{2}$ emissions of specific transport modes. The last part represents further influential factors which may cause a change in the behavior of the SC. Today politics and media are an important example. A political decision such as fees for railways in a country may have an effect on SC transport pathes. An example for the influential power of the media could be the advertising of the new law of France, called "Grenelle II" (June 2010), which declares that from July 2011 the carbon footprint label on products is mandatory rather than voluntary. It is likely that the discussion of this law in the media abroad will increase the interest of consumers in other countries regarding this topic and lead them to search for such kind of products, which may result in a pressure on domestic companies to demonstrate their environment-friendliness. 


\subsection{Simulation Approach for Green Supply Chains}

There are two kinds of information classes - internal and external - which influence the level of SC flexibility as demonstrated in the previous section. Based on these conceptual parts there are various scenarios with different key aspects. The first key aspect is the external one, as an enterprise likes to know which impact external factors will have on their (current or future) supply chain. The second key aspect relates to the design options that an enterprise considers for their supply chain. The resulting research space is the crossproduct of both sets of scenarios, enabling the search for the future SC that can face future external factors with the most adequate flexibility with acceptable economical and environmental KPIs.

The internal factors will form the knowledge base for the SC design scenarios. As an example for a physical SC network, we can imagine to add an additional node, e.g., representing a warehouse, to the existing network in its potential geographical location. A simulation experiment will evaluate the "To Be" SC under the given constraint of the physical network and as a result supports the decision about changes on the logical network. By adding the policies to the scenario parameters we gain the ability to evaluate different arrangements of rules. The results generated in this way can be used to select the best set of rules for different tasks (Hicks 1999). The method how to select the best policies is not in the scope of this paper.

The external factors serve as a further basis for simulation input. From the data point of view, these factors represent the external flexibility requirements, because their initial values, changes and fluctuations will be a measure for the SC flexibility. The flexibility of the SC will determine if the SC can react in an effective and successful manner or if undesirable effects will occur.

As already implemented for ICON-SimChain (cp. chapter 3), the simulation experiments can be automatically deduced from a SC scenario, based on template libraries. The scope of the template library is limited by the scope of the $\mathrm{SC}$ - for example, there is no need to design a template for an assembly station if this is not part of the SC model scope.

The results of experiment series act as flexibility evaluation. One possible use of this outcome is to study how flexible a given system will behave in relation to external factors. The second use of these results is acting as knowledge basis for the improvement of the SC with respect to green aspects, leading e.g., to redesigning the physical network or designing and remodeling policies on the logical network layer.

\subsection{Flexibility Example}

In order to gain a practical impression of the flexibility approach, an illustration is given of an example which explains the discussed issue of external factors with respect to the scope of $\mathrm{CO}_{2}$ reduction and its practical benefit for SC flexibility. The scenario is formulated as "How should I design my SC in order to be less vulnerable to a nationwide strike? The design of the SC is related to both views - the physical network and the business logic. We assume that a set of policies describes the business options for intermediate storage of goods. The set of all possible choices is given by the SC network serving as constraint for the simulation scenario. Furthermore, the policies can contain additional information in the form of supplementary knowledge. In our example they include goods which are probably the most "important" products for the next week. The definition of "most important" depends on the SC context - we can imagine that it is the main product of a new marketing campaign, the product with the greatest financial reward, or simply an external factor - the customer demand of a product, which leads to a requirement as "a delay of the good is not acceptable". The specific simulation application template is the basis for simulating different "To Be" scenarios (e.g., using $<$ Second Warehouse $>$ and $<$ Fifth warehouse $>$ instead) and taking business knowledge into account. The resulting different emission KPIs enable for choosing the alternative storage option with the fewest $\mathrm{CO}_{2}$ emissions. This increases the flexibility of the GSC because if one of the storages is not available, simulation delivers the KPIs as decision support to choose the next alternative storage with low $\mathrm{CO}_{2}$ emissions. Therefore the company is able to react more flexible to external distractions in their GSC. 
While this sample for illustrative purposes just considers one single external factor, the flexibility of the SC will have to be measured with respect to its ability to react to a large set of possible fluctuations. Here, the notion of risk comes into discussion, as deviations from the standard SC behaviour can be better accepted if the risk for this external development is low. A method to calculate overall flexibility KPIs taking risk evaluation into account is not considered for this paper, but appears to be an interesting research field in order to substantially judge the SC flexibility based on simulation experiments.

\section{CONCLUSION}

In this paper we have discussed special flexibility from the organizational perspective, the logistics dimension and the tactical aspect on an aggregate level. In addition, flexibility characteristics where introduced in the "green" context of $\mathrm{CO}_{2}$ reduction. The approach has pointed out that flexibility of GSCs can be analysed by an adequate combination of data representation, simulation and supporting mechanisms. As always, measurement is the basis for improvement, and thus the flexibility analysis is the starting point to optimize GSCs for most flexibly reacting to external influence. We have illustrated that a list of entities is needed to build up the model. These entities are mainly a data mart with conceptually divided parts where flexibility requirements and design scenarios can be derived from and a simulation framework that uses templates to conduct the flexibility evaluation. To address the data mart concept which serves both as collaboration storage and organization of data we propose a collaboration platform. It will support the architecture requirements in a manner that ontologies, interfaces or different data layers can be integrated.

The first steps to realize this platform approach are taken in a currently running European project (FP7-ICT-288585, started 01.01.2012), called Energy Efficiency in the Supply Chain through Collaboration, Advanced Decision Support and Automatic Sensing (e-SAVE). The aim of this initiative is to support the design and operation of energy-efficient SCs in the consumer goods sector. It will deliver the system, services, collaboration platform and management tools that will permit companies to monitor, manage and share energy use and carbon footprint data. Exploiting this platform, operational as well as strategic decision making and SC design decisions can be supported. In this context, the authors will conduct further research to implement the principles of studying flexibility in GSC as presented in this paper in a simulation environment cooperating with a collaboration platform.

\section{REFERENCES}

Alicke, K., and K. Gutenschwager. 2003. "Supply Chain Simulation mit ICON-SimChain." In: Logistik Management: Prozesse, Systeme, Ausbildung, Edited by T. Spengler, S. Voß, and H. Kopfer, 161178, Heidelberg, Physica.

Araujo, L., and M. Spring. 2002. "Manufacturing Flexibility and Industrial Networks." 18th IMP Conference ESC, Dijon, France, CD ROM publication.

Awwad, Ab., and S. Almahamid. 2008. "The Link between Modification Flexibility and Organizational Objectives: an Empirical Study on Jordanian Manufacturing Companies.” Journal of Social Sciences 4:293-307.

Banks, J., S. Buckley, S. Jain, P. Lendermann, and M. Manivannan. 2002. "Panel Session: Opportunities for Simulation in Supply Chain Management". In Proceedings of the 2002 Winter Simulation Conference, Edited by J. L. Snowdon, J. M. Charnes, E. Yücesan, and C.-H. Chen, 1652-1658. Piscataway, New Jersey: IEEE.

Bertrand, J. W. M. 2003. "Supply Chain Design: Flexibility Considerations." Handbooks in OR \& MS, No. 11, 133-198. Amsterdam, Netherlands: Elsevier.

Bowersox, D. J., and D.J. Closs. 1996. Logistics Management: the Integrated Supply Chain Process. New York, New York: Mc Graw and Hill.

Carlsson, B. 1989. "Flexibility and the Theory of the Firm." International Journal of Industrial Organization 7:179-203. Amsterdam, Netherlands: Elsevier. 
Chang, Y., and H. Makatsoris. 2001. "Supply Chain Modeling using Simulation.” Simulation 2:24-30. Berlin, Germany: Springer Verlag.

Chenga, J.C. 2011. "A Web Service Framework for Measuring and Monitoring Environmental and Carbon Footprint in Construction Supply Chains". Procedia Engineering 14:141-147. Amsterdam, Netherlands: Elsevier.

Child, J. 1972. "Organizational Structure, Environment and Performance: The Role of Strategic Choice." Sociology 6:2-22. Thousand Oaks, California: SAGE Publications.

Clausen, U., and Hesse, K. 2008. "Nachhaltige Gestaltung der Logistik". Duisport Magazin, No. 4/2008, 19-21. Duisburg, Germany: Duisburger Hafen AG.

Davis, T. 1993. "Effective Supply Chain Management." Sloan Management Review, Summer 1993, 3546. Cambride, Massachusetts: Massachusetts Institute of Technology.

Day, G. S. 1994. "The Capabilities of Market-driven Organizations." Journal of Marketing 58:37-52. Boston, Massechusetts: American Marketing Association.

Diabat, A., and D. Simchi-Levi. 2010. "A Carbon-capped Supply Chain Network Problem." IEEE International Conference on Industrial Engineering and Engineering Management, 2009, 523-527. Piscataway, New Jersey: Institute of Electrical and Electronics Engineers.

Green, K., and B. Morton, S. New. 1996. "Purchasing and Environmental Management: Interactions, Policies and Opportunties". Business Strategy and the Environment 5:188-197. Manchester, United Kingdom: CROMTEC, UMIST.

Godfrey, R. 1998. "Ethical Purchasing: Developing the Supply Chain beyond Environment." Greener Purchasing: Opportunities and Innovations, Edited by T. Russel, 244-251. Sheffield, United Kingdom: Greenleaf Publishing.

Hellström, D., M. Johnsson. 2002. "Using Discrete-event Simulation in Supply Chain Planning." 14th Annual Conference for Nordic Researchers in Logistics. Trondheim, Norway: NOFOMA

Hervani, A.A., M.M. Helms, and J. Sarkis. 2005. "Performance Measurement for Green Supply Chain Management". Benchmarking 12:330-353. Bradford, United Kingdom: Emerald Group Publishing Limited.

Hicks, D.A. 1999. "A Four Step Methodology for Using Simulation and Optimization Technologies in Strategic Supply Chain Planning." In Proceedings of the 31st Winter Simulation Conference, Volume 2, Edited by A. Phillip, Farrington, H. B. Nembhard, W. G. Evans, and D.T. Sturrock, 1215-1220. New York: Institute of Electrical and Electronical Engineers.

International Organization for Standardization (ISO). 2007. ISO 14000-Series Environment Management Systems.

Kleijnen, J. P. C. 2005. Supply Chain Simulation Tools and Techniques: A Survey. In: International Journal of Simulation and Process Modelling 1:82-89.

Koste, L.L., and M.K. Malhotra. 1999. "A Theoretical Framework for Analyzing the Dimensions of Manufacturing Flexibility." Journal of Operations Management 18:75-93. Amsterdam, Netherlands: Elsevier.

Lavington, F. 1921. The English Capital Market. London: Methuen \& Co.

Lindskog, E., and J. Berglund. 2011. "A Method for Detemining the Enviromental Footprint of Industrial Products using Simulation." In Proceedings of the 2011 Winter Simulation Conference, Edited by L. Lundh, J. Berglund, Y.T. Lee, A. Skoogh, and B. Johannson, 2131-2142. New York: Institute of Electrical and Electronical Engineers.

Liu, J. 1999. "Data Mart: Next Step in Data Storage". Term Paper. Boulder, Colorado: University of Colorado.

Parimala, N., and P.Pahwa. 2006. "Coalescing Data Marts". In Proceedings of XVI International Conference on Computer and Information Science and Engineering (CISE), 280-285. Turtle Bay Resort, Honolulu, Hawaii: IEEE ICCCN. 
Perry, J. H. 1991. "Emerging Economic and Technological Futures: Implications for Design and Management of Logistics Systems in the 1990s." Journal of Business Logistics 12:1-16. Lombard, Illinois: CSCMP.

Rabe, M., and M. Deininger. 2012. "State of Art and Research Demands for Simulation Modeling of Green Supply Chains." International Journal of Automation Technology 6:296-303. Tokyo, Japan: Fuji Technology Press Co., Ltd.

Rao, P., and D. Holt. 2005. "Do Green Supply Chains Lead to Competitiveness and Economic Performance?" International Journal of Operations \& Production Management 25:898-916. Bradford, United Kingdom: Emerald Group Publishing Limited.

Sánchez A.M., and M. Pérez Pérez, (2005) "Supply Chain Flexibility and Firm Performance: A Conceptual Model and Empirical Study in the Automotive Industry." International Journal of Operations \& Production Management 25:681-700. Bradford, United Kingdom: Emerald Group Publishing Limited.

Schulz, M., and S. Spieckermann. 2008. "Logistics Simulation in the Chemical Industry." In: Logistic Optimization of Chemical Production Processes, Edited by S. Engell, 21-36, Chichester, Wiley.

Sethi, A. K., and S.P. Sethi. 1990. "Flexibility in Manufacturing: a Survey." International Journal of Flexible Manufacturing Systems 2:289-328. Berlin, Germany: Springer Verlag.

Stigler, G. 1939. "Production and Distribution in the Short Run." Journal of Political Economy 47:305-327. Chicago, Illinois: University of Chicago Press.

Straube, F., and S. Doch. 2011."A Contribution to Sustainable Logistics and Supply Chain - Conceptual Design to Evaluate Ecological and Economical Cause-Effect Relations in Logistics Planning Processes." In Advances in Sustainable Manufacturing, Edited by G. Seliger, M.K. Khraisheh, and I.S. Jawahir, 353-364. Berlin, Germany: Springer Verlag.

Suarez, F. F., M. A. Cusumano, and C. F. Fine. 1991. Flexibility and Performance: A Literature Critique and Strategic Framework. Sloan School of Management Working Paper. 3298-91. Cambridge, MA, Massachusetts Institute of Technology.

Terzi, S., and S. Cavalieri. 2004. "Simulation in the Supply Chain Context: A Survey." In Computers in Industry 53:3-16.

Upton, D. 1994. "The Management of Manufacturing Flexibility." California Management Review 36:72-89. Bradford, United Kingdom: Emerald Group Publishing Limited.

Van Slooten, W.M.C. 2009. The Role of CO2 Footprint during Order Acquisition. MSc Thesis, Faculty of Technology, Policy and Management, 1-20. Delft, Netherlands, Delft University of Technology.

Wadhwa, S., and K.S. Rao. 2003. Enterprise Modeling of Supply Chains Involving Multiple Entity Flows: Role of Flexibility in Enhancing Lead Time Performance. Studies in Informatics and Control. Pasing City, Philippines: ICI Publishing House.

Zhang, Q., M. A. Vonderembse, and J.-S. Lim. 2002a. Product Development Flexibility: Testing Relationships among Competence, Capability and Customer Satisfaction. Arkansas State University and The University of Toledo.

Zhang, Q., M. A. Vonderembse, and J.-S. Lim. 2002b. "Value Chain Flexibility: a Dichotomy of Competence and Capability." International Journal of Production Research 40:561-583. London, United Kingdom: Taylor \& Francis.

Zhang, Q., M. A. Vonderembse, and J.-S. Lim. 2003. "Manufacturing Flexibility: Defining and Analyzing Relationships among Competence, Capability, and Customer Satisfaction." Journal of Operations Management 21:173-191. Amsterdam, Netherlands: Elsevier.

Zhang, Q., M. A. Vonderembse, and J.-S. Lim. 2005. "Logistics Flexibility and its Impact on Customer Satisfaction." International Journal of Logistics Management 16:71-95. Amsterdam, Netherlands: Elsevier.

Zhang, Q., M. A. Vonderembse, and J.-S. Lim 2006. "Spanning Flexibility: Supply Chain Information Dissemination Drives Strategy Development and Customer Satisfaction." Supply Chain Management 11:390-399. Amsterdam, Netherlands: Elsevier. 
Zhang, Q., M.A. Vonderembse, and M. Cao. 2009. "Product Concept and Prototype Flexibility in Manufacturing: Implications for Customer Satisfaction." European Journal of Operational Research 194:143-154. Amsterdam, Netherlands: Elsevier.

\section{AUTHOR BIOGRAPHIES}

MARKUS RABE is full professor for IT in production and logistics at the Technical University Dortmund. Until 2010 he had been with Fraunhofer IPK in Berlin as head of the corporate logistics and processes department, head of the central IT department and member of the institute direction circle. His research focus is on information systems for supply chains, production planning and simulation. Markus Rabe is vice chair of the "Simulation in Production and Logistics" group of the simulation society ASIM, member of the editorial board of the Journal of Simulation, member of several conference program committees, has chaired the ASIM SPL conference in 1998, 2000, 2004, and 2008, and is local chair of the WSC'2012 in Berlin. More than 150 publications and editions report from his work. His e-mail address is markus.rabe@tu-dortmund.de.

SVEN SPIECKERMANN is Chief Executive Officer at SimPlan AG, Maintal, Germany, mainly working as a senior consultant and project manager in simulation projects for several industries. Since 1992, he has been participating in over 200 simulation projects. Additionally, he has been giving lectures in simulation at the Technical University of Braunschweig since 1995 and at the Technical University of Darmstadt since 2008. He has published several papers on simulation, simulation-based optimization and related topics. His e-mail address is sven.spieckermann@simplan.de.

ADRIENN HORVATH is since 2011 a research assistant at the Technical University Dortmund, IT in Produktion and Logistik. She studied Business and Management at the Budapest University of Technology and Economics and graduated with a thesis on innovation supporting mechanisms. Her research focus is environment-friendly supply chains. Her e-mail address is adrienn.horvarth@tu-dortmund.de.

TILL FECHTELER is Branch Manager at SimPlan AG, Braunschweig, Germany, mainly working as a senior consultant and project manager in simulation projects. Since 1997, he has been participating in more than 100 simulation projects for several industries. His e-mail address is till.fechteler@simplan.de. 